\title{
Research
}

Damian RJ Martínez-St John, Antonio Palazón-Bru, Vicente F Gil-Guillén, Armina Sepehri, Felipe Navarro-Cremades, Dolores Ramírez-Prado, Domingo Orozco-Beltrán,

Concepción Carratalá-Munuera, Ernesto Cortés and María M Rizo-Baeza

\section{Diagnostic inertia in obesity and the impact on cardiovascular risk in primary care:}

\author{
a cross-sectional study
}

\begin{abstract}
Background

Prevalence of diagnostic inertia (DI), defined as a failure to diagnose disease, has not been analysed in patients with obesity.

Aim

To quantify DI for cardiovascular risk factors (CVRF) in patients with obesity, and determine its association with the cardiovascular risk score.

\section{Design and setting}

Cross-sectional study of people $\geq 40$ years attending a preventive programme in primary healthcare centres in Spain in 2003-2004.

\section{Method}

All patients with obesity attending during the first 6 months of the preventive programme were analysed. Participants had to be free of CVD (myocardial ischaemia or stroke) and aged 40-65 years; the criteria used to measure SCORE (Systematic COronary Risk Evaluation). Three subgroups of patients with obesity with no personal history of CVRF but with poor control of

\section{INTRODUCTION}

Cardiovascular disease (CVD) is the leading cause of mortality, according to the World Health Organization. ${ }^{1}$ The main modifiable risk factors are obesity, hypertension, diabetes, dyslipidaemia, and smoking. ${ }^{2}$ In addition, high blood pressure (HBP), high blood cholesterol (HBC), and high blood glucose levels are more prevalent in patients with obesity. ${ }^{3}$ For this reason, the detection and control of cardiovascular risk factors (CVRF) in patients with obesity is highly recommended. ${ }^{4}$

Clinical inertia, also known as therapeutic inertia, has been defined as a failure to start or intensify therapy when indicated by clinical guidelines. ${ }^{5}$ The factors associated with therapeutic inertia have been studied in an integrative review. These were by defined by Anjoulat et al as:
\end{abstract} risk factors were established. Outcome variable was DI, defined as poor control of risk factors and no action taken by the physician. Secondary variables were diabetes, fasting blood glucose (FBG), body mass index (BMII), and SCORE. Adjusted odds ratios (OR) was determined using multivariate logistic regression models.

\section{Results}

Of 8687 patients with obesity in the programme, 6230 fulfilled SCORE criteria. Prevalence of $\mathrm{Dl}$ in the three subgroups was: hypertension 1275/1816 (70.2\%) patients affected (95\% $\mathrm{Cl}=68.1$ to $72.3 \%)$; diabetes, 335/359 (93.3\%) patients affected $(95 \% \mathrm{Cl}=90.7$ to $95.9 \%)$; dyslipidaemia subgroup, 1796/3341 (53.8\%) patients affected $195 \% \mathrm{Cl}=52.1$ to $55.4 \%$. Factors associated with DI for each subgroup were: for hypertension, absence of diabetes, higher BMI, and greater cardiovascular risk; for dyslipidaemia, diabetes, higher BMI, and greater cardiovascular risk (SCORE); and for diabetes, lower FBG levels, lower BMl, and greater cardiovascular risk

\section{Conclusion}

This study quantified Dl in patients with obesity and determined that it was associated with a greater cardiovascular risk.

\section{Keywords}

diabetes mellitus; dyslipidaemias; hypertension; inertia; obesity; physician's practice patterns; primary health care. providers' knowledge of and attitudes toward evidence-based guidelines, providers' own clinical judgment; providers awareness of patients' attitudes, behaviours, and preferences; and providers' ability to make decisions in specific clinical contexts.

In a recent review, Lebeau etal determined

DRJ Martínez-St John, PhD, clinical researcher

A Sepehri, PhD, clinical researcher;

F Navarro-Cremades, MD, PhD, clinical

researcher and professor; D Orozco-Beltrán, MD

$\mathrm{PhD}$, clinical researcher and professor

C Carratalá-Munuera, MD, PhD, clinical

researcher and professor, Department of Clinical

Medicine; E Cortés, PhD, clinical researcher and professor, Department of Pharmacology,

Pediatrics, and Organic Chemistry, Miguel

Hernández University, San Juan de Alicante,

Spain. A Palazón-Bru, PhD, biostatistician, clinical researcher and medical writer; VF Gil-Guillén,

MD, PhD, clinical researcher and professor,

Department of Clinical Medicine, Miguel

Hernández University, San Juan de Alicante,

and Research Unit, Elda Hospital, Elda, Spain.

D Ramírez-Prado, PhD, clinical researcher,

Research Unit, Elda Hospital, Elda, Spain. that Gil-Guillén et al distinguished diagnostic inertia from therapeutic inertia, as follows:

Diagnostic inertia was identified when a patient without known hypertension had high blood pressure but was labelled "normal" by the medical staff ..." 8

Furthermore, they found an inverse association between body mass index (BMI) and inertia in hypertensive patients. ${ }^{8}$ The concept of diagnostic inertia has also been studied in dyslipidaemia.

In the Valencian Community in Spain, a free-of-charge health screening preventive programme was carried out between September 2003 and December 2004 from at primary healthcare centres. The Government invited all individuals aged $\geq 40$ years to attend their health centre for a check-up that included cardiovascular and gynaecological screenings, and a vaccination campaign. ${ }^{10}$

Data from this preventive programmewere used in the present study to determine the rates of diagnostic inertia for hypertension, diabetes, and dyslipidaemia in obese individuals, and the association between this inertia and the cardiovascular risk score

MM Rizo-Baeza, PhD, clinical researcher and professor, Department of Nursing. University of Alicante, San Vicente del Raspeig, Spain.

\section{Address for correspondence}

Antonio Palazón-Bru, Department of Clinical Medicine, Miguel Hernández University, Carretera de Valencia - Alicante S/N, 03550, San Juan de Alicante, Spain.

E-mail: antonio.pb23dgmail.com

Submitted: 9 October 2014; Editor's response: 15 December 2015; final acceptance: 13 February 2015.

\section{CBritish Journal of General Practice}

This is the full-length article (published online 29 Jun 2015) of an abridged version published in print. Cite this article as: $\mathbf{B r} \mathbf{J}$ Gen Pract 2015; DOI: 10.3399/bjgp15X685669 


\section{How this fits in}

Diagnostic inertia is defined as nonadherence to clinical guidelines for diagnosing diseases. To the authors' knowledge no previous studies have analysed diagnostic inertia solely in obese patients. In this study the issue of diagnostic inertia in obesity was assessed. The prevalence of inertia was very high for all cardiovascular risk factors. This association between inertia and cardiovascular risk was surprising because a higher cardiovascular risk was associated with this inertia. This issue should be avoided in clinical practice.

was analysed. ${ }^{11}$ Other studies have analysed diagnostic inertia and its association with a personal history of CVRF., However, none have examined cardiovascular risk using a scoring system such as SCORE (Systematic COronary Risk Evaluation). ${ }^{11}$ SCORE is a system that calculates the probability of cardiovascular mortality in individuals aged 40-65 years that are free of CVD.

Although, Sepehri et al examined this association in patients with obesity, inertia was defined as a lack of advice to lose weight. ${ }^{10}$

This is an important distinction because cardiovascular risk scores consider the current status of patients rather than the personal history of CVRF. ${ }^{10}$

Therefore, by considering cardiovascular risk in the obese population, this study could determine whether there are gaps in detecting CVRF and, as a consequence, reduce the incidence of CVD.

\section{METHOD}

\section{Study population}

People living in the Valencian Community, aged $\geq 40$ years, who attended their health centre for the preventive health screening programme were included in the study. These patients have a high prevalence of CVRF. The majority are female, of an older age, and attend their health centre frequently. ${ }^{12}$

\section{Study design and participants}

A cross-sectional study was performed in which all patients with obesity (BMI $\geq 30 \mathrm{~kg} /$ $\mathrm{m}^{2}$ ) who attended their health centre voluntarily during the first 6 months of the preventive programme were analysed. To qualify for the study patients had to be free of CVD (myocardial ischaemia or stroke) and aged 40-65 years. These are the criteria used to measure SCORE. ${ }^{11}$ Three subgroups of obese patients were established:
- Those with no personal history of hypertension but with high blood pressure (HBP) ( $\geq 140 / 90 \mathrm{mmHg}$, or $\geq 130 / 80 \mathrm{mmHg}$ for patients with diabetes). ${ }^{13}$

- Those with no personal history of diabetes but with high fasting blood glucose (HFBG) values ( $\geq 7.0 \mathrm{mmol} / \mathrm{L}) .^{14}$

- Those with no personal history of dyslipidaemia but with $\mathrm{HBC}$ values (total cholesterol $\geq 5.17 \mathrm{mmol} / \mathrm{L}) .^{15}$

The cut-off points for the diagnosis of these CVRF are equivalent to those defined in UK and European guidelines. ${ }^{16-19}$ The three groups were not independent; a patient could belong to one, two, or all three of the groups, or to none of them.

Use of the database was approved in 2007 and this study (determining the research question, literature and statistical analysis, and drafting of the article) was started in March 2014.

The physicians in the study were blinded to its aim of determining the prevalence of diagnostic inertia. They were only aware of the requirement to perform the preventive programme correctly.

\section{Variables and measurements}

In each subgroup the outcome variable was diagnostic inertia, defined as having high values of control parameters (HBP, HFBG, and HBC) but with no action taken by the physician. It would be expected that any action to be taken would occur once the patient had received blood test results, blood pressure measurement, a personal clinical interview, and had their $\mathrm{BMI}$ calculated. All tests and the physician's action were recorded on the same morning.

The secondary variables were sex, personal history of CVRF (hypertension, diabetes, dyslipidaemia, and smokingl, age (years), blood pressure (systolic/diastolic, $\mathrm{mmHg}$ ), total cholesterol (mmol/L), fasting blood glucose (FBG) (mmol/L), BMI ( $\mathrm{kg} /$ $\mathrm{m}^{2}$ ) and SCORE (\%). SCORE was calculated using the variables sex, age, systolic blood pressure, total cholesterol, and smoking. ${ }^{11}$ Outcomes and secondary variables were measured using guidelines in force when the study was undertaken. . $^{13-15}$

Blood pressure was recorded as the mean of two measurements taken using a validated and calibrated device. BMI was calculated by measuring weight and height with calibrated devices, without shoes, and removing all objects that could affect weight. Blood was drawn at the start of the morning after an 8-hour fast and measured using calibrated devices to obtain readings for total cholesterol and fasting blood glucose. 


\section{Sample size}

The sample group consisted of 1816 patients with unknown hypertension who had HBP 3341 with unknown dyslipidaemia who had $\mathrm{HBC}$, and 359 with unknown diabetes who had HFBG. The sample size calculation was therefore performed later. ${ }^{20}$ With a $95 \%$ confidence, an expected proportion of 50\% (maximum), and with the aim of estimating the prevalence of inertia (the main study objective), errors of $2.3 \%, 1.7 \%$, and $5.2 \%$, respectively, were obtained.

\section{Statistical analysis}

Absolute and relative frequencies were used to describe the qualitative variables, and the mean and standard deviation for quantitative variables. In each subgroup, a logistic regression model was constructed to determine which variables were associated with diagnostic inertia. Using this model the adjusted odds ratios (ORs) were determined. These ORs were adjusted for SCORE, $\mathrm{BMI}$, and a personal history of diabetes. In patients who had diabetes, FBG was used instead of a personal history of diabetes. The remaining variables were not introduced into the models due to collinearity issues. The predicted probability of inertia was calculated in the models and represented in graph form to aid understanding. The goodness of fit of the models was assessed by the likelihood ratio test. All the analyses were done with an $\alpha=5 \%$ and the associated confidence interval (CI) was calculated for each relevant parameter. All the analyses were done with IBM SPSS Statistics 19.

\section{RESULTS}

An outline of the process is given in Figure 1. A total of 33440 people attended their health centres to participate in the preventive programme. Of these, 8687 were obese and 6230 fulfilled the criteria to calculate the SCORE laged 40-65years and free of CVD). Of these, 2044 patients belonged to none of the groups, 2942 to just one group (hypertension 693, dyslipidaemia 2151, and diabetes 98), 1158 to two groups (hypertension and dyslipidaemia 983, hypertension and diabetes 54, dyslipidaemia and diabetes 121) and 86 to all three groups.

The first subgroup lunknown hypertension with HBPJ consisted of 1816 patients, of whom 1275 (70.2\%) experienced inertia (95\% Cl=68.1 to $72.3 \%$ ). The subgroup of patients with unknown diabetes and HFBG consisted of 359 people, 335 (93.3\%) of whom experienced inertia $(95 \% \mathrm{Cl}=90.7$ to $95.9 \%)$. The subgroup with unknown dyslipidaemia and high HBC consisted of 3341 patients, of whom 1796 (53.8\%) experienced inertia (95\% $\mathrm{Cl}=52.1$ to $55.4 \%$ ).

The descriptive and analytical characteristics of the sample are shown in Table 1. The high prevalence of CVRF was reflected in the overall range values of hypertension (22.4-32.3\%), diabetes (4.4-7.4\%), dyslipidaemia (9.3-14.8\%), and smoking (20.7-23.7\%). Sex also varied (male $39.5-51.3 \%$ ), the average age ranged from $53.1-53.7$ years, the average BMI was 33.3$34.5 \mathrm{~kg} / \mathrm{m}^{2}$, and the average SCORE was $1.6-$ $2.1 \%$. In the hypertension subgroup a greater probability of diagnostic inertiawas associated with no personal history of diabetes IOR 0.18, $95 \% \mathrm{Cl}=0.12$ to $0.26, P<0.0011$, a higher $\mathrm{BMI}$ (per $\left.1 \mathrm{~kg} / \mathrm{m}^{2}\right) \quad(\mathrm{OR}=1.05,95 \% \mathrm{Cl}=1.02$ to 1.09, $P=0.005$ ) and a greater SCORE (per $1 \%)$ (OR $1.11,95 \% \mathrm{Cl}=1.05$ to $1.18, P<0.001$ ). In the dyslipidaemia subgroup the associated factors were a personal history of diabetes (OR $1.29,95 \% \mathrm{Cl}=0.91$ to $1.82, P=0.156$ ), a higher BMI (per $1 \mathrm{~kg} / \mathrm{m}^{2}$ ) (OR 1.01, 95\% $\mathrm{Cl}=0.98$ to $1.03, P=0.628$ ), and a greater SCORE (per $1 \%$ ) (OR $1.25,95 \% \mathrm{Cl}=1.19$ to 1.31, $P<0.001)$. In the diabetes subgroup a greater probability of diagnostic inertia was associated with lower FBG figures levels (per $1 \mathrm{mmo} / \mathrm{L})(\mathrm{OR} 0.99,95 \% \mathrm{Cl}=0.99$ to 1.00, $P=0.008)$, a higher BMl (per $1 \mathrm{~kg} / \mathrm{m}^{2}$ ) (OR $0.99,95 \% \mathrm{Cl}=0.89$ to $1.11, P=0.901$ ) and a greater SCORE (per 1\%) (OR 1.16, 95\% $\mathrm{Cl}=0.89$ to $1.50, P=0.266)$.

The relationship between SCORE risk and diagnostic inertia in each subgroup is shown in Figure 2. In these Cartesian graphs the predicted probability is plotted on the $Y$ axis and the SCORE risk on the $X$ axis. Symbols were used to distinguish whether a patient had a personal history of diabetes. The graphs demonstrate the increase in the probability of inertia in relation to the 
Table 1. Analysis of inertia for recognising cardiovascular risk factors in obese patients at primary healthcare centres

\begin{tabular}{|c|c|c|c|c|c|c|}
\hline Variable & $\begin{array}{c}\text { Unknown } \\
\text { hypertension } \\
\text { with HBP } \\
n=1816 \\
\text { Inertia: } n=1275\end{array}$ & $\begin{array}{c}\text { Adjusted OR } \\
\text { for inertia } \\
(95 \% \mathrm{Cl})^{\mathrm{a}}\end{array}$ & $\begin{array}{c}\text { Unknown } \\
\text { dyslipidaemia } \\
\text { with high TC } \\
n=3341 \\
\text { Inertia: } n=1796\end{array}$ & $\begin{array}{l}\text { Adjusted OR } \\
\text { for inertia } \\
(95 \% \mathrm{Cl})^{\mathrm{b}}\end{array}$ & $\begin{array}{c}\text { Unknown } \\
\text { diabetes with } \\
\text { high FBG } \\
n=359 \\
\text { Inertia: } n=335\end{array}$ & $\begin{array}{c}\text { Adjusted OR } \\
\text { for inertia } \\
(95 \% \mathrm{Cl})^{c}\end{array}$ \\
\hline Male sex $n(\%)$ & $858(47.2)$ & - & 1320 (39.5) & - & $184(51.3)$ & - \\
\hline $\begin{array}{l}\text { Personal history of hypertension, } \\
n[\%]\end{array}$ & - & - & $750(22.4)$ & - & 116 (32.3) & - \\
\hline Personal history of dyslipidaemia, $n(\%)$ & $169(9.3)$ & - & - & - & $53(14.8)$ & - \\
\hline Personal history of diabetes, $n(\%)$ & $135(7.4)$ & $\begin{array}{c}0.18 \\
(0.12 \text { to } 0.26)\end{array}$ & $148(4.4)$ & $\begin{array}{c}1.29 \\
\text { (0.91 to } 1.82)\end{array}$ & - & - \\
\hline Personal history of smoking, $n(\%)$ & $383(21.1)$ & - & $690(20.7)$ & - & $85(23.7)$ & - \\
\hline Age, years, mean $\pm S D$ & $53.2 \pm 7.1$ & - & $53.1 \pm 7.1$ & - & $53.7 \pm 7.0$ & - \\
\hline $\mathrm{SBP}, \mathrm{mmHg}$, mean $\pm \mathrm{SD}$ & $144.6 \pm 13.4$ & - & $133.2 \pm 16.8$ & - & $139.3 \pm 19.7$ & - \\
\hline $\mathrm{DBP}, \mathrm{mmHg}$, mean $\pm \mathrm{SD}$ & $88.3 \pm 8.8$ & - & $81.9 \pm 10.2$ & - & $84.8 \pm 11.4$ & - \\
\hline $\mathrm{TC}, \mathrm{mmol} / \mathrm{L}$, mean $\pm \mathrm{SD}$ & $5.6 \pm 1.0$ & - & $6.0 \pm 0.8$ & - & $5.6 \pm 1.2$ & - \\
\hline $\mathrm{FBG}, \mathrm{mmol} / \mathrm{L}$, mean $\pm \mathrm{SD}$ & $6.0 \pm 2.0$ & - & $5.7 \pm 1.6$ & - & $8.8 \pm 3.2$ & $\begin{array}{c}0.99 \\
(0.99 \text { to } 1.00)\end{array}$ \\
\hline $\mathrm{BMI}, \mathrm{kg} / \mathrm{m}^{2}$, mean $\pm \mathrm{SD}$ & $33.4 \pm 3.2$ & $\begin{array}{c}1.05 \\
\text { (1.02 to } 1.09)\end{array}$ & $33.3 \pm 3.2$ & $\begin{array}{c}1.01 \\
\text { (0.98 to } 1.03)\end{array}$ & $34.5 \pm 3.9$ & $\begin{array}{c}0.99 \\
\text { (0.89 to } 1.11 \text { ) }\end{array}$ \\
\hline SCORE, $\%$, mean \pm SD & $2.0 \pm 2.3$ & $\begin{array}{c}1.11 \\
\text { (1.05 to } 1.18)\end{array}$ & $1.6 \pm 2.6$ & $\begin{array}{c}1.25 \\
\text { (1.19 to } 1.31)\end{array}$ & $2.1 \pm 2.9$ & $\begin{array}{c}1.16 \\
\text { (0.89 to } 1.50)\end{array}$ \\
\hline \multicolumn{7}{|c|}{ 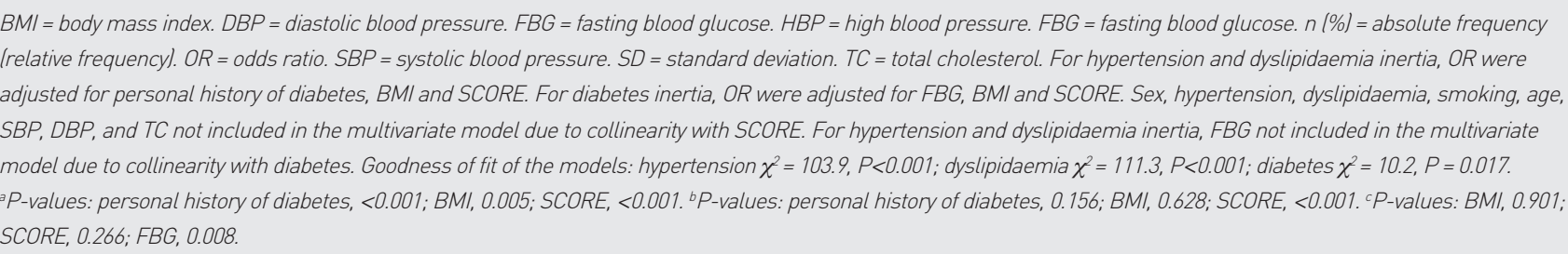 } \\
\hline
\end{tabular}

Figure 2. Predicted probabilities of diagnostic inertia and their relationship with the SCORE cardiovascular risk in hypertension, diabetes and dyslipidaemia. 2003-2004 data, Spain.

$P$-values correspond to the goodness-of-fit of the multivariate models. greater cardiovascular risk (SCORE). The variables in the graphs were a personal history of diabetes and SCORE. SCORE was included as a variable because it relates to the main CVRF (hypertension, diabetes, older age, male sex, smoking, and dyslipidaemial and diabetes was included because it is not a predictive variable in SCORE. ${ }^{1 !}$

\section{DISCUSSION}

\section{Summary}

This study found that diagnostic inertia was prevalent; seven out of every 10 obese patients who fulfilled the criteria for HBP were not followed-up by their physicians in order to confirm or discard a diagnosis of hypertension, nine out of 10 patients with
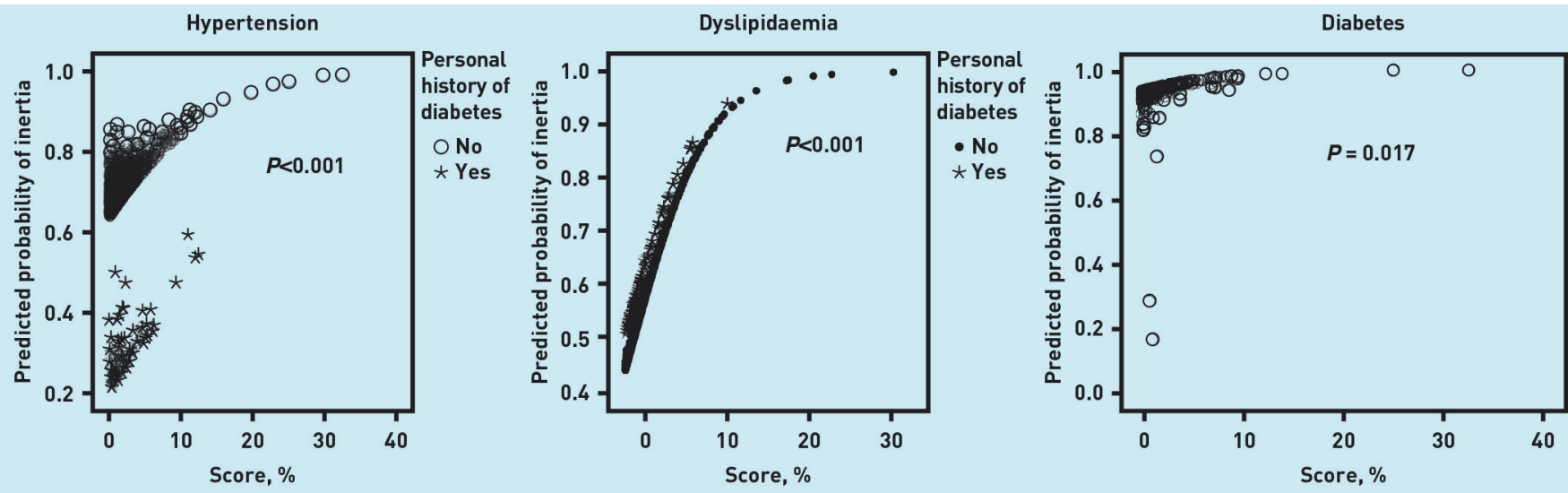
HFBG were not followed up for diabetes, and one-half of the patients who had HBC were not investigated for dyslipidaemia. It also shown that a greater cardiovascular risk was associated with a higher probability of inertia. This probability increased by between $11-25 \%$ (OR 1.11 to 1.25 ) for every $1 \%$ increase in cardiovascular risk (SCORE).

\section{Strengths and limitations}

The main strength of this study is that it is the first to deal with failure to detect CVRF in patients with obesity. The results show that physicians who should be diagnosing CVRF are failing to adhere to clinical guidelines; in other words, diagnostic inertia. The results also indicate that diagnostic inertia is associated with a greater cardiovascular risk. This is an issue that needs to be investigated further. The study design defined the limitations. There was selection bias, as only the patients who attended a preventive health screening programme were included. It would be interesting to replicate this study in general clinical practice. Information bias was minimised by the use of calibrated devices. The failure to include physician variables, such as age, sex, or training is a further limitation of the study.

Finally, although data were used from 2003-2004, diagnostic inertia remains a problem decades after it was detected in the 1980s. ${ }^{21}$ However, it was not defined as inertia at that time, and still remains a relevant subject of study. ${ }^{9}$ Clinical guidelines are constantly being updated and cut-off control parameters modified, but diagnostic inertia still exists.

\section{Comparison with existing literature}

Other studies have assessed the relationship between diagnostic inertia and CVRF in dyslipidaemia and hypertension. In relation to hypertension, a higher level of inertia was found in persons who smoked, had diabetes, coronary heart disease, or lower blood pressure, and had lower BMI. Studies that analysed inertia in dyslipidaemia have found that patients with a high cardiovascular risk were more likely to have abnormal highdensity lipoprotein cholesterol levels but no diagnosis of dyslipidaemia. ${ }^{8.9}$ These results are generally in accordance with the current study, as a greater cardiovascular risk was associated with inertia. This could be due to the fact that most patients had multiple disorders and were polymedicated, so that the healthcare professional decided not to increase the therapeutic complexity of the patient. However, as these studies included patients both with and without obesity, it is difficult to compare findings.

Only one study analysed inertia in patients with obesity. ${ }^{10}$ Inertia was defined as a lack of advice to lose weight. This study and the current analysis determine the relationship between inertia and a cardiovascular risk score. The current study shows the same association as the previous one; that is, a greater risk score in patients with inertia. ${ }^{10}$

The findings were unexpected as these patients have a higher probability of cardiovascular death if no preventive measures are taken. Like Sepehri et al, the authors believe that physicians are focusing on the personal history of CVRF, rather than on the actual status of the patient. In other words, physicians do not consider blood pressure, FBG, or cholesterol levels, as they are concentrating more on the personal history of disease. Consequently, they do not calculate the cardiovascular risk score. ${ }^{10}$

\section{Implications for research and practice}

This study highlights a problem in situations where a patient has high control parameters but is not followed-up by the physician to confirm or discard a diagnosis of other CVRF, in addition to their cardiovascular risk due to obesity. The authors expected the prevalence of diagnostic inertia to be low, but in fact found that in all CVRF it was high (53.8-93.3\%). Furthermore, patients with obesity, who already have a higher probability of cardiovascular mortality, had high rates of diagnostic inertia as the cardiovascular risk increased (OR 1.11 to 1.25).

Finally, this study was performed during a cardiovascular health screening preventive programme. Overall, considering that diagnostic inertia during this preventive programme was found to be frequent, it would be interesting to know what the situation is in daily clinical practice. In primary care settings physicians use their own judgement to decide whether to request tests or take action, as opposed to this preventive programme in which all patients were screened. A possible solution to prevent diagnostic inertia may be to integrate alarm systems into health records. For example, whenever a physician accesses the records of a patient with abnormal control parameters, this could be flagged up by a recognisable sound or a flashing light. Another approach would be to perform a qualitative (focus group) study to determine why family physicians do not follow clinical guidelines when diagnosing CVRF. This would also have relevance in the UK, because inertia is a prevalent problem that can affect patient outcomes. ${ }^{22}$ 


\section{REFERENCES}

1. World Health Organization. The top 10 causes of death. http://who.int/ mediacentre/factsheets/fs310/en/ laccessed 19 May 2015).

2. World Health Organization. Prevention of cardiovascular disease: Guideline for assessment and management of cardiovascular risk. 2007. http://whqlibdoc. who.int/publications/2007/9789241547178_eng.pdf?ua=1 laccessed 19 May 2015)

3. Center for Disease Control and Prevention (CDC). Obesity: Halting the epidemic by making health easier. 2011. http://www.cdc.gov/chronicdisease/resources/ publications/aag/pdf/2011/Obesity_AAG_WEB_508.pdf laccessed 2 Jun 2015).

4. Clinical guidelines on the identification, evaluation, and treatment of overweight and obesity in adults - the evidence report. National Institutes of Health. Obes Res 1998; 6: 51S-209S. [Erratum in: Obes Res 1998; 6: 464.]

5. Andrade SE, Gurwitz JH, Field TS, et al. Hypertension management: the care gap between clinical guidelines and clinical practice. Am J Manag Care 2004; 10: $481-486$.

6. Aujoulat I, Jacquemin P, Rietzschel E, et al. Factors associated with clinical inertia: an integrative review. Adv Med Educ Pract 2014; 5: 141-147.

7. Lebeau JP, Cadwallader JS, Aubin-Auger I, et al. The concept and definition of therapeutic inertia in hypertension in primary care: a qualitative systematic review. BMC Fam Pract 2014; 15: 130.

8. Gil-Guillén V, Orozco-Beltrán D, Pérez RP, et al. Clinical inertia in diagnosis and treatment of hypertension in primary care: quantification and associated factors. Blood Press 2010; 19: 3-10.

9. Palazón-Bru A, Gil-Guillén VF, Orozco-Beltrán D, et al. Is the physician’s behavior in dyslipidemia diagnosis in accordance with guidelines? Crosssectional ESCARVAL study. PLoS One 2014; 9: e91567.

10. Sepehri A, Gil-Guillén VF, Palazón-Bru A, et al. Are obese patients assisted in losing weight? Am J Manag Care 2014; 20: e122-128.

11. Conroy RM, Pyörälä K, Fitzgerald AP, et al. SCORE project group. Estimation of ten-year risk of fatal cardiovascular disease in Europe: the SCORE project. Eur Heart J 2003; 24: 987-1003.

12. Pedrera Carbonell V, Gil Guillén V, Orozco Beltrán D, et al. Characteristics of health care demand in family medical clinics in a health area of the community of Valencia. [In Spanish]. Aten Primaria 2005; 35: 82-88
13. Chobanian AV, Bakris GL, Black HR, et al. Joint National Committee on Prevention, Detection, Evaluation, and Treatment of High Blood Pressure. National Heart, Lung, and Blood Institute; National High Blood Pressure Education Program Coordinating Committee. Seventh report of the Joint National Committee on Prevention, Detection, Evaluation, and Treatment of High Blood Pressure. Hypertension 2003; 42: 1206-1252

14. American Diabetes Association. Screening for type 2 diabetes. Diabet Care 2003; 26: s21-24.

15. National Cholesterol Education Program (NCEP) Expert Panel on Detection, Evaluation, and Treatment of High Blood Cholesterol in Adults (Adult Treatment Panel III). Third report of the National Cholesterol Education Program (NCEP) Expert Panel on Detection, Evaluation, and Treatment of High Blood Cholesterol in Adults (Adult Treatment Panel III) final report. Circulation 2002; 106: 3143-3421.

16. Williams B, Poulter NR, Brown MJ, et al. BHS guidelines working party, for the British Hypertension Society. British Hypertension Society guidelines for hypertension management 2004 (BHS-IV): summary. Br Med J 2004; 328 634-640. Erratum in: Br Med J 2004; 328: 926.

17. National Institute for Clinical Excellence. Management of type 2 diabetes management of blood glucose. NICE Inherited Clinical Guideline G. London: NICE, 2002.

18. British Cardiac Society; British Hypertension Society; Diabetes UK; HEART UK Primary Care Cardiovascular Society; Stroke Association. JBS 2: Joint British Societies' guidelines on prevention of cardiovascular disease in clinical practice. Heart 2005: 91 Suppl 5: v1-52.

19. De Backer G, Ambrosioni E, Borch-Johnsen K, et al. European guidelines on cardiovascular disease prevention in clinical practice. Third Joint Task Force of European and Other Societies on Cardiovascular Disease Prevention in Clinical Practice. Eur Heart J 2003; 24: 1601-1610.

20. Cohen J. Statistical power analysis for the behavioral sciences. 2nd edn. Mahwah, NJ: Lawrence Erlbaum Associates, 1988

21. Bell MM, Dippe SE. Recognition and treatment of hypercholesterolemia in a family practice center. J Fam Pract 1988; 26: 507-513.

22. Maher J, Bates M, Carmody P. The effect of clinical inertia on the management of blood pressure [letter]. Br J Gen Pract 2014; 64: 278. 